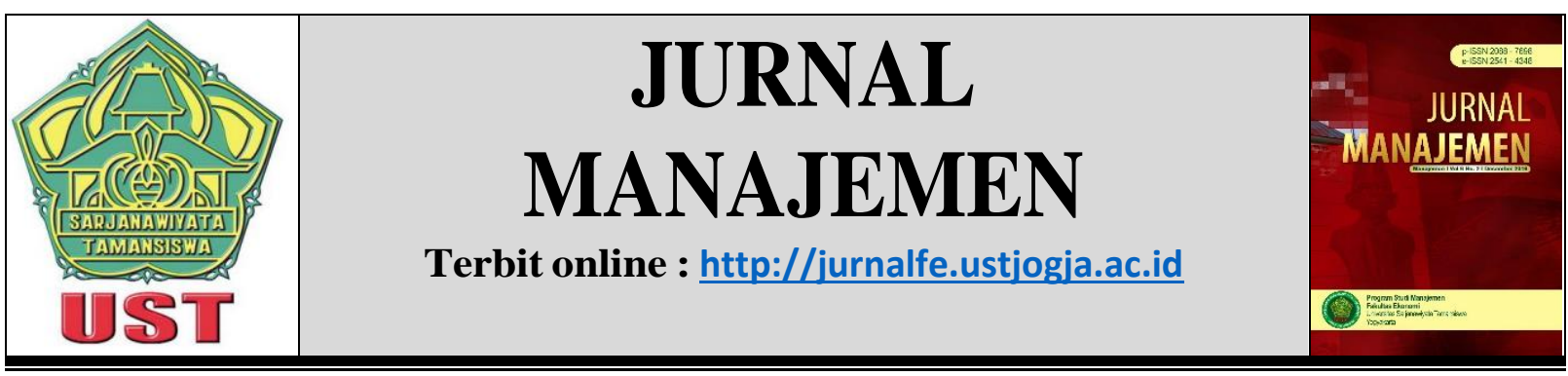

\title{
PENGARUH KEMAMPUAN KERJA, KEPUASAN KERJA DAN KOMITMEN ORGANISASI TERHADAP KINERJA KARYAWAN PD. BPR BKK KEBUMEN
}

\section{Hesty Mei Putriana', Jajuk Herawati ${ }^{2}$}

\author{
Universitas Sarjanawiyata Tamansiswa Yogyakarta ${ }^{1,2}$
}

Korespondensi : hestymei3@gmail.com

\begin{tabular}{ll}
\hline Informasi Naskah & Abstrak \\
\hline Diterima: & The purpose of this study was to analyze the effect of work ability \\
28 Mei 2018 & on employee performance, the effect of job satisfaction on \\
Revisi: & employee performance, the influence of organizational \\
4 Juni 2018 & commitment to employee performance, and the effect of variable \\
Terbit: & ability to work, job satisfaction and organizational commitment \\
6 Juni 2018 & on the performance of PD. BPR BKK Kebumen. The sampling \\
\hline Kata Kunci: ability to & technique was accidental sampling. Data collection using a \\
work, job satisfaction,, & questionnaire, while data analysis techniques using multiple \\
organizational & regression analysis by the F-test and T-test and the classical \\
commitment, & assumption test of normality test, multicollinearity test, and \\
performance & heteroscedasticity. The results showed the multiple linier \\
& regression model is $Y=51,096-0,263 X_{1}-0,305 X_{2}+0,293 X_{3}$. \\
& That is ability to work, job satisfaction, and organizational \\
& commitment contributes greatly to the performance. Value of the \\
& determinant coefficient $\left(R^{2}\right)$ was $0,158$. The result shoe that the \\
& coefficient determinant of ability to work, job satisfaction, and \\
& organizational commitment have a positive influence on employee \\
& performance by $15,8 \%$ and the remaining $84,2 \%$ is influenced by \\
& otherfactors.
\end{tabular}

\section{PENDAHULUAN}

Dalam menghadapi perkembangan dunia bisnis di Indonesia saat ini, perusahaan dituntut untuk selalu mampu mempertahankan dan meningkatkan kualitas kerjanya dengan berpartisipasi secara terencana, terarah, efektif dan efisien. Hal ini dimaksudkan demi terwujudnya perusahaan yang unggul dan siap bersaing. Dan salah satu kunci sukses untuk memenangkan persaingan adalah kebutuhan akan sumber daya manusia yang berkualitas. Sumber daya manusia dalam sebuah perusahaan menempati peranan yang penting karena berperan sebagai penggerak akan kemana, bagaimana dan seperti apa organisasi dijalankan. 
Beberapa faktor yang dapat mempengaruhi kinerja karyawan antara lain yaitu kemampuan kerja. Seperti yang di ungkapkan oleh Robbins (1998), bahwa kemampuan adalah kapasitas seseorang individu untuk mengerjakan berbagai tugas dalam suatu pekerjaan. Seseorang yang memiliki kemampuan berarti akan sanggup melakukan tugastugas yang dibebankan kepadanya. Dapat dikatakan bahwa dengan kemampuan yang dimiliki oleh pegawai akan memudahkan dalam penyelesaian setiap pekerjaan secara efektif dan efisien tanpa adanya kesulitan sehingga akan menghasilkan suatu pekerjaan atau kierja yang baik.

Selain itu masih ada faktor lain yaitu kepuasan kerja, Husain Umar (2008:213) menyatakan bahwa Kepuasan kerja adalah perasaan dan penilaian seorang atas pekerjaannya, khususnya menegenai kondisi kerjanya, dalam hubungannya dengan apakah pekerjaannya mampu memenuhi harapan, kebutuhan, dan keinginannya. Faktor yang dapat mempengaruhi kepuasan kerja, diantaranya yaitu gaji, pimpinan, rekan kerja, kondisi kerja, dan lain-lain. Kepuasan kerja merupakan aspek pertama yang dicapai sebelum seseorang karyawan memiliki komitmen organisasi. Kepuasan kerja memiliki pengaruh yang signifikan terhadap komitmen organisasi. Sehingga komitmen organisasi memiliki hubungan yang erat dalam mempengaruhi kinerja karyawan. Komitmen tersebut dapat terwujud apabila organisasi dapat memberi perhatian dan perlakuan baik serta membuat karyawan percaya terhadap organisasi dengan adanya pendekatan manajemen terhadap karyawan sebagai asset berharga dan tidak semata-mata sebagai komoditas yang dapat dieksploitasi sekehendak manajemen. Jika organisasi mendapat dukungan penuh dari karyawan, usaha pencapaian tujuan organisasi akan semakin terkonsentrasi dan diprioritaskan. Untuk itu, penelitian ini menguji secara empiris kemampuan kerja berpengaruh terhadap kinerja karyawan, kepuasan kerja berpengaruh terhadap kinerja karyawan, komitmen organisasi berpengaruh terhadap kinerja karyawan, kemampuan kerja dan kepuasan kerja dan komitmen organisasi secara simultan berpengaruh terhadap kinerja karyawan.

\section{KAJIAN TEORI}

1. Kemampuan kerja

Pengertian mampu menurut Wojowasito (1995) adalah kesanggupan atau kecakapan, sedangkan kemampuan berarti seseorang yang memiliki kecakapan atau kesanggupan untuk menjalankan sesuatu yang diwujudkan melalui tindakannya untuk meningkatkan produktivitas kerjanya. Menurut Gibson (1994:104) kemampuan menunjukan potensi orang untuk melaksanakan tugas atau pekerjaan. Kemampuan itu mungkin dimanfaatkan atau mungkin juga tidak. Kemampuan berhubungan erat dengan kemampuan fisik dan mental yang dimiliki orang untuk melaksanakan pekerjaan dan bukan yang ingin dilakukan. Menurut Hasibuan (2003:94) Kemampuan kerja adalah suatu hasil kerja yang dicapai seseorang dalam melaksanakan tugas-tugas yang dibebankan kepadanya yang didasarkan atas kecakapan, pengalaman dan kesungguhan serta waktu. Dari pendapat tersebut dapat dikatakan bahwa dengan kemampuan yang dimiliki oleh pegawai akan memudahkan dalam penyelesaian setiap pekerjaan secara efektif dan efisien tanpa adanya kesulitan sehingga akan menghasilkan suatu pekerjaan atau kierja yang baik.

2. Kepuasan Kerja

Menurut Robbins (2002:36) Kepuasan kerja merupakan sikap umum seorang karyawan terhadap pekerjaannya. Kepuasan kerja menunjukkan adanya kesesuaian antara harapan seseorang yang timbul dengan imbalan yang disediakan oleh pekerjaan. Menurut Kamus Besar Bahasa Indonesia, Kepuasan kerja berarti keadaan psikis yang menyenangkan yang dirasakan oleh pekerja dalam suatu lingkungan pekerjaan karena terpenuhinya semua kebutuhan secara memadai. 


\section{Komitmen Organisasi}

Robbins (2001) komitmen pada organisasi merupakan suatu keadaan dimana seorang karyawan memihak pada suatu organisasi dan tujuan-tujuannya, serta berniat memelihara keanggotaan dalam organisasi itu.

Dalam penelitian Porter dan Steers (dalam Luthans, 1992:125) menunjukkan bahwa komitmen yang tinggi berpengaruh terhadap tingginya tingkat performansi. Selain itu seseorang yang mempunyai tingkat komitmen yang tinggi terhadap organisasinya cenderung untuk bertahan sebagai anggota dalam waktu yang relatif panjang. Individu yang memiliki komitmen yang rendah pada organisasi seringkali hanya menunggu kesempatan yang baik untuk keluar dari pekerjaan mereka. Komitmen terhadap organisasi artinya lebih dari sekedar keanggotaan formal, karena meliputi sikap menyukai organisasi dan kesediaan untuk mengusahakan tingkat upaya yang tinggi bagi kepentingan organisasi demi pencapaian tujuan.

4. Kinerja

Menurut Rivai dan Basri (2005:50) Kinerja karyawan merupakan hasil atau tingkat keberhasilan seseorang secara keseluruhan selama periode tertentu dalam melaksanakan tugas dibandingkan dengan berbagai kemungkinan, seperti standart hasil kerja, target atau sasaran atau kriteria yang telah ditentukan terlebih dahulu telah disepakati bersama.

Menurut Robbins (1996) Kinerja merupakan fungsi dari kemampuan, motivasi, dan kesempatan. Dengan kata lain, kinerja ditentukan oleh faktor-faktor kemampuan, motivasi dan kesempatan. Kesempatan kerja adalah rintangan-rintangan kinerja yang tinggi sebagian merupakan fungsi dari tiadanya rintangan-rintangan pengendali karyawan itu. Bila sampai pada penelitian mengapa seorang karyawan tidak menghasilkan kinerja pada suatu tingkat yang seharusnya dia mampu, maka perlu diperiksa lingkungan kerjanya untuk melihat apakah mendukung atau tidak terhadap pelaksanaan pekerjaannya. Jadi kinerja yang optimal selain didorong oleh kuatnya motivasi seseorang dan tingkat kemampuan yang memadai, juga didukung oleh lingkungan yang kondusif.

\section{METODOLOGI PENELITIAN}

Dalam penelitian ini jenis yang digunakan adalah penelitian deskriptif dengan pendekatan penelitian kuantitatif. Sugiyono (2011:29) mendefinisikan statistik deskriptif adalah statistik yang berfungsi untuk mendiskripsikan atau memberi gambaran terhadap objek yang diteliti melalui data sampel atau populasi sebagaimana adanya tanpa melakukan analisis dan membuat kesimpulan yang berlaku untuk umum.

Lokasi atau tempat penelitian ini dilaksanakan di PD BPR BKK Kebumen. Data diperoleh dengan menyebarkan kuesioner terhadap karyawan atau pengrajin perak di daerah Kebumen yang diambil sebagai sampel 70 karyawan. Penyebaran kuesioner dilaksanakan mulai tanggal 7-18 Maret 2016.

Untuk pengujian hipotesis, menggunakan analisis regresi berganda. Analisis ini memiliki tujuan untuk mengetahui pengaruh langsung terhadap hubungan variabelvariabel dalam penelitian. Dalam penelitian ini terdapat empat variabel, yaitu variabel dependen yang digunakan adalah kinerja. Variabel independen terdiri dari kemampuan kerja, kepuasan kerja, komitmen organisasi. 


\section{HASIL DAN PEMBAHASAN}

Tabel 1 Hasil Uji Koefisien determinan $\mathbf{R}^{2}$

\begin{tabular}{lrrrr}
\hline Model & $\mathrm{R}$ & R Square & Adjusted R Square & $\begin{array}{r}\text { Std. Error of } \\
\text { the Estimate }\end{array}$ \\
\hline 1 & $.441^{\mathrm{a}}$ & .194 & .158 & 4.56972 \\
\hline
\end{tabular}

a. Predictors: (Constant), X3, X1, X2

b. Dependent Variable: Y

Sumber: Data primer, 2016 diolah

Berdasarkan tabel 1 diatas dapat diketahui bahwa nilai Adjusted $R$ Square sebesar 0,158 . Hal ini menjelaskan bahwa kontribusi variabel kemampuan kerja, kepuasan kerja dan komitmen organisasi mempengaruhi variabel dependen Y sebesar 15,8\%. Sedangkan sisanya sebesar $(100 \%-15,8=84,2 \%)$ dipengaruhi oleh variabel lain yang tidak ada dalam penelitian ini.

Tabel 2 Hasil Uji t

\begin{tabular}{|c|c|c|c|c|c|c|}
\hline \multirow{2}{*}{\multicolumn{2}{|c|}{ Model }} & \multicolumn{2}{|c|}{$\begin{array}{l}\text { Unstandardized } \\
\text { Coefficients }\end{array}$} & \multicolumn{3}{|c|}{$\begin{array}{l}\text { Standardized } \\
\text { Coefficients }\end{array}$} \\
\hline & & B & Std. Error & Beta & $\mathrm{T}$ & Sig. \\
\hline \multirow[t]{4}{*}{$\overline{1}$} & (Constant) & 51.096 & 6.219 & & 8.216 & .000 \\
\hline & Kemampuan & -.263 & .119 & -.250 & -2.218 & .030 \\
\hline & Kepuasan & -.305 & .107 & -.319 & -2.850 & .006 \\
\hline & Komitmen & .293 & .115 & .285 & 2.546 & .013 \\
\hline \multicolumn{7}{|c|}{ a. Dependent Variable: Y } \\
\hline
\end{tabular}

Sumber: Data primer, 2016 diolah

Dari hasil penelitian ini dengan melihat tabel coefficients kita dapat mengetahui hasil regresi berganda dalam bentuk persamaan yaitu : $\mathbf{Y}=\mathbf{5 1 , 0 9 6}-\mathbf{0 , 2 6 3 X _ { 1 } - \mathbf { 0 , 3 0 5 X }} \mathbf{2}+$ $\mathbf{0 , 2 9 3 X}_{\mathbf{3}}+\mathbf{e}$, Yang berarti bahwa variabel independen $\mathrm{X} 1$ (Kemampuan Kerja) mempengaruhi Y (Kinerja) sebesar -0,263, variabel X2 (Kepuasan Kerja) mempengaruhi Y (Kinerja) sebesar -0,305. X3 (Komitmen Organisasi) mempengaruhi Y (Kinerja) sebesar 0,293.

Selain itu dari hasil uji hipotesis 1 berdasarkan tabel (uji t) menunjukkan bahwa $t$ hitung sebesar -2,218 $>\mathrm{t}$ tabel 1,668 dengan nilai signifikansi 0,030 $<0,05$, yang berarti bahwa hipotesis dalam penelitian ini menolak Ho dan menerima Ha. sehingga kemampuan kerja berpengaruh negatif terhadap kinerja karyawan. Temuan beta menunjukan negatif signifikan yang artinya semakin melemahnya nilai kemampuan kerja tetapi kinerja meningkat. Ada kemungkinan beberapa variabel lain yang belum diteliti setelah variabel kemampuan kerja mempengaruhi meningkatnya kinerja karyawan.

Hasil uji hipotesis 2 berdasarkan tabel (uji t) menunjukkan bahwa t hitung sebesar $2.850>\mathrm{t}$ tabel 1,668 dengan nilai signifikansi $0,006<0,05$, yang berarti bahwa hipotesis dalam penelitian ini menerima Ha dan menolak Ho. Pada pengujian ini secara statistik membuktikan bahwa kepuasan kerja berpengaruh negatif terhadap kinerja karyawan. Temuan beta menunjukan negatif signifikan yang artinya semakin melemahnya nilai kepuasan kerja tetapi kinerja karyawan meningkat. Ada kemungkinan beberapa variabel lain yang belum diteliti setelah variabel kepuasan kerja mempengaruhi meningkatnya kinerja karyawan.

Hasil uji hipotesis 3 berdasarkan tabel (uji t) variabel komitmen organisasi terhadap Kinerja karyawan PD. BPR BKK Kebumen menunjukan pengaruh yang signifikan yaitu t hitung sebesar $2.546>\mathrm{t}$ tabel 1668 dengan nilai signifikansi $0,013<0,05$, ini berarti 
variabel komitmen organisasi berpengaruh signifikan terhadap kinerja. Semakin tinggi tingkat komitmen organisasi semakin baik pula tingkat kinerja karyawan.

Tabel 3 Hasil Uji Simultan (Uji F)

\begin{tabular}{lllllll}
\hline Model & Sum of Squares & Df & Mean Square & F & Sig. \\
\hline 1 & Regression & 332.067 & 3 & 110.689 & 5.301 & $.002^{\mathrm{a}}$ \\
& Residual & 1378.233 & 66 & 20.882 & & \\
\multicolumn{1}{l}{ Total } & 1710.300 & 69 & & & \\
\hline
\end{tabular}

a. Predictors: (Constant), X3, X1, X2

b. Dependent Variable: $\mathrm{Y}$

Sumber: Data primer, 2016 diolah

Hasil Uji Hipotesis 4 :

Pengaruh variabel independen X1 (Kemampuan Kerja), X2 (Kepuasan Kerja), dan X3 (Komitmen Organisasi) terhadap variabel dependen Y (Kinerja Karyawan). Hasil uji hipotesis dapat dilihat pada tabel diatas, nilai $\mathrm{F}$ diperoleh sebesar 5.301 dengan tingkat kesalahan 5\%, dimana $\mathrm{F}$ tabel $=2,74$ ternyata $\mathrm{F}$ hitung $>\mathrm{F}$ tabel $(5.301>2,74)$, dengan demikian $\mathrm{F}$ hitung $>\mathrm{F}$ tabel sehingga $\mathrm{H} 0$ ditolak dan Ha diterima, ini menunjukkan bahwa secara simultan antara variabel independen X1 (Kemampuan Kerja), X2 (Kepuasan Kerja), dan X3 (Komitmen Organisasi) berpengaruh terhadap variabel dependen $\mathrm{Y}$ (Kinerja kKryawan)

\section{KESIMPULAN}

1. Berdasarkan uji hipotesis, Variabel kemampuan kerja (X1) memiliki pengaruh negatif tetapi signifikan terhadap kinerja. Dengan nilai koefisien regresi sebesar -2.218. Hasil tersebut mengindikasikan semakin tinggi kemampuan kerja maka kinerja akan semakin menurun. Dengan hasil uji t nilai signifikansi sebesar 0,030 lebih rendah dari 0,05 sehingga hipotesis yang menyatakan "ada pengaruh signifikan kemampuan kerja terhadap kinerja karyawan" dapat diterima.

2. Berdasarkan uji hipotesis, Variabel kepuasan kerja (X1) memiliki pengaruh negatif tetapi signifikan terhadap kinerja. Dengan nilai koefisien regresi sebesar -2.850. Hasil tersebut mengindikasikan semakin tinggi kepuasan kerja maka kinerja akan semakin menurun. Dengan hasil uji t nilai signifikansi sebesar 0,006 lebih rendah dari 0,05 sehingga hipotesis yang menyatakan "ada pengaruh signifikan kepuasan kerja terhadap kinerja karyawan" dapat diterima.

3. Berdasarkan uji hipotesis, variabel komitmen organisasi (X3) berpengaruh positif secara signifikan terhadap kinerja karyawan PD. BPR BKK Kebumen, hal ini berarti semakin tinggi tingkat Komitmen karyawan terhadap organisasi maka dapat meningkatkan kinerja karyawan PD. BPR BKK Kebumen.

4. Dan berdasarkan hasil uji $\mathrm{F}$ menunjukan $\mathrm{F}$ hitung sebesar 5,301 dengan tingkat signifikansi 0,002. Karena signifikansi lebih kecil dari 0,05, sehingga diartikan bahwa variabel kemampuan kerja, kepuasan kerja dan komitmen organisasi berpengaruh signifikan secara bersama-sama (simultan) terhadap kinerja karyawan PD. BPR BKK Kebumen.

\section{REFERENSI}

Allen, N.J \& Mayer, J.P., 1993. Organizational commitment: Evidence of career stage effects? Journal of Business Research, 26, 49-61

Alviani, Indah. 2013. Analisis Pengaruh Internal Locus Of Control,Komitmen Organisasi dan Job Insecurity Terhadap Kinerja Karyawan PT. Mitra Bisnis Keluarga Kutowinangun. Kebumen: Sekolah Tinggi Ilmu Ekonomi (STIE) Putra Bangsa 
Arikunto, Suharsimi. 2002. Prosedur Penelitian: Suatu Pendekatan Praktik, Edisi Revisi. Yogyakarta: Graha Ilmu

Arnold, Hugh J. and Daniael C. Feldman. 1986. Organizational Behavior. McGraw-Hill. New York.

Danuarta, Adad. 2014. Manajemen Sumberdaya Manusia, Kepuasan Kerja. Diakses pada Jum'at tanggal 07 November 2014, 22:07

Dessler, Garry. 2007. Human Resources Management, Jilid 2 (Terjemah). Jakarta: PT. Prenhallindo

Dessler, Garry. 2000. Human Resource Management $8^{\text {th }}$ edition, New Jersey: Prentice Hall, Inc

Farlen, Frans. 2011. Pengaruh Motivasi Kerja Dan Kemampuan Kerja Terhadap Kinerja Karyawan (Studi pada karyawan PT. United Tractors, Tbk Samarinda). Yogyakarta: Fakultas Ilmu Sosial dan Ilmu Politik Universitas Pembangunan Nasional "VETERAN"

Fauzi, Ahmad. 2014. Kemampuan Kerja Karyawan. http:// www.yaspemainsidi.com/2013/03/kemampuan-kerja-karyawan.html?m=1. Diakses pada tanggal 1 Maret 2013, 20:02

Ghozali, Imam. 2008. Aplikasi Analisis Multivariate dengan Program SPSS. Semarang: Universitas Diponegoro

Ghozali, Imam. 2011. "Aplikasi analisis multivariate dengan program IBM 19 edisi lima spss”. Semarang:badan penerbit UNDIP

Gibson \& Ivancevich dkk. 1994. Organisasi dan Manajemen. Perilaku, struktur, proses. Edisi keempat. Jakarta: Erlangga

Gibson, 1998. Organisasi dan Manajemen Terjemahan Ichayaudin Zahud. Jakarta: Erlangga

Hadi, Sutrisno. 2004. Metodologi Riset Jilid II. Yogyakarta: Penerbit Andi Offset

Handoko, T. Hani. 2001. Manajemen Personalia dan SDM. Edisi ke dua. Yogyakarta: BPFE

Hasibuan, Malayu SP. 2003. Manajemen Sumber Daya Manusia. Edisi Revisi. Jakarta: PT Bumi Aksara

Kamus Besar Bahasa Indonesia On Line. Pusat Bahasa Departemen Pendidikan Nasional republik Indonesia

Luthans, F. 1992. Organizational Behavior. Singapore: McGraw Hill

Luthans, Fred. 2006. Perilaku Organisasi. Yogyakarta: Penerbit Andi

Mangkunegara. 2000. Manajemen Sumber Daya Manusia Perusahaan. Bandung: PT. Remaja Rosdakarya

Mangkunegara, Anwar Prabu. 2002. Manajemen Sumber Daya Manusia Perusahaan. Bandung : PT. Remaja Rosdakarya

Mas'ud, Fuad. 2004. Survai Diagnosis Organisasional, Konsep \& Aplikasi. Semarang: Badan Penerbit Universitas Diponegoro

Mathis R.L dan Jackson J.H. 2006. Manajemen Sumber daya Manusia. Salemba Empat. Edisi Kesepuluh. Jakarta

Mink. 1993. Seri Manajemen Sumber Daya Manusia (Kinerja/Performance). Jakarta: PT Elik Media Koputindo

Mitchel T.R., 1982. People in Organization: in Introduction to Organization Behavior, MC.Graw Hill Book Comp. Tokyo

Prawirosentono, Suryadi. 1999. Kebijakan Kinerja Karyawan. Yogyakarta: BPFE

Rivai, Veithzal \& Basri. 2005. Performance Appraisal: Sistem yang tepat untuk Menilai Kinerja Karyawan dan Meningkatkan Daya Saing Perusahaan. Jakarta: PT. Raja Grafindo Persada. 
Rivai Veithzal dan Juavani, E.S. 2010. Manajemen Sumber Daya Manusia Untuk Perusahaan (dari Teori ke Praktik). Jakarta: Raja Grafindo Persada

Robbins, Stephen P., 1998. Perilaku Organisasi. Edisi Bahasa Indonesia Cetakan Ke 2. Prenhallindo: Jakarta

Robbins, Stephen P. 2001. Perilaku Organisasi. Jakarta: PT. Prehallindo.

Robbis, Stephen. 2002. Prinsip-Prinsip Perilaku Organisasi. Jakarta : Erlangga.

Santosa, singgih. 2003. Riset Pemasaran, Konsep dan Aplikasi dengan SPSS 12. Jakarta: PT. Elex Media Kumpotindo

Siagian, Sondang. 1992. Organisasi Kepemimpinan dan Perilaku Administrasi. Jakarta: Gunung Agung

Sopiah. 2008. Perilaku Organisasional. Yogyakarta: Andi

Sugiyono. 2005. Statistik Untuk Penelitian dan Aplikasinya dengan SPSS 10 For Windows. Bandung: Penerbit Alfabeta

Sugiyono. 2008. Metode penelitian Bisnis. CV. Alfabeta. Bandung

Sugiyono, 2009. Metode Penelitian Kuantitatif, Kualitatif dan R\&D. Bandung: Penerbit Alfabeta

Steers, R.M and Porter, L.W., 1983. Motivation and Work Behavior. Accademic Press. New York

Umar, Husein. 2008. Riset Sumber Daya Manusia Dalam Organisasi. Jakarta: Ghalia Indonesia

Wiyono, Gendro. 2011. Merancang Penelitian Bisnis, Dengan Alat Analisis SPSS 17.0 \& SmartPLS 2.0. Yogyakarta: UPP STIM YKPN 